\title{
Research of the Obtaining Process of Protective Phosphate Nanocoatings
}

\author{
LAURA AIKOZOVA ${ }^{1}$, AINUR TUKIBAYEVA ${ }^{1 \star}$ and MARAT SATAYEV ${ }^{2}$ \\ ${ }^{1}$ Department of Chemistry, M. Auezov South Kazakhstan State University, South-Kazakhstan region, \\ Republic of Kazakhstan. \\ ²Department of Life safety, M.Auezov South Kazakhstan State University, South-Kazakhstan region, \\ Republic of Kazakhstan. \\ ${ }^{\star}$ Corresponding author E-mail: ainur_tukibaeva@mail.r \\ http://dx.doi.org/10.13005/ojc/350127
}

Received: October 13, 2018; Accepted: January 21, 2019)

\begin{abstract}
This article presents thermodynamic calculations of the interaction of zinc and iron chlorides with phosphoric acid. The influence of temperature and duration of the interaction on the degree of decomposition of metal chlorides is also determined. It is established that with increasing the temperature and the duration of interaction, the degree of conversion of zinc and iron chlorides to metal phosphates increases and the residual chlorine content in the product simultaneously decreases. The quality control of the obtained products was carried out using physical, chemical and crystal-optical methods of analysis.
\end{abstract}

Keywords: Phosphates, Zinc and iron chlorides, Phosphoric acid, Metal phosphates, Metal corrosion.

\section{INTRODUCTION}

The protection of metal and structural products from corrosion is one of the most important problems of great importance for the national economy.

In this regard, one of the topical problems is to obtain anti-corrosive protective nanostructured coatings from production waste and reduce import substitution products.

Phosphate nanocoatings are one of the types of products obtained as a result of the interaction of the metal with a solution of phosphoric acid. These nanocoatings are a crystalline films of phosphate salts of iron and manganese or iron and zinc that are sparingly soluble in water. Such salts are stable under atmospheric conditions, in lubricating oils and organic solvents, but are destroyed in acids and alkalis. Phosphate coatings have high electrical resistance and withstand a voltage of up to $250 \mathrm{~V}$, and after impregnation with insulating oils-up to $1000 \mathrm{~V}^{1}$.

Phosphate nanocoatings are not wetted with molten metal, and this property is used in metallurgical production. The phosphate layer,

This is an Open Access article licensed under a Creative Commons license: Attribution 4.0 International (CC- BY). Published by Oriental Scientific Publishing Company @ 2018 
impregnated with lubricants, favorably affects the processes of wire drawing, drawing pipes, stamping and transporting oil2.

The carbon and low-alloy steels, cast iron, some non-ferrous and light metals can be subjected to phosphatization.

In recent years, more attention has been paid to the phosphatizing of non-ferrous metals. Processes of phosphatizing zinc, cadmium, nickel, covar alloy, etc. have been developed. The film formed on such metals consists mainly of four-water tertiary zinc phosphate. Zinc-resistant film to corrosion on cadmium is formed for $10-20 \mathrm{~min}$ on nickel and covar for 30-40 minutes. In solutions containing accelerator additives, the duration of cadmium phosphatizing can be reduced to 5-10 min zinc up to 3-5 minutes. Painting coatings, applied on nickel by phosphate ground are suitable for products operating in a humid atmosphere ${ }^{3}$.

Some authors ${ }^{4}$ developed the composition and methods of application of phosphate and chromium coats. Proposed method includes treatment of surface first with phosphatizing solution of the following composition, $\mathrm{g}^{-\mathrm{L}^{-1}}$ : zinc monosulfate, 12-14; zinc nitrate, 18-22; sodium phosphate, 5-10; orthophosphoric acid, 4-5 and remainder being water; then phosphatizing in solution at concentration of $15-30 \mathrm{~g} / \mathrm{l}$ and impregnation of coat in solution at concentration of 80-100 g- $\mathrm{L}^{-1}$ are performed followed by drying at temperature of $100-120^{\circ} \mathrm{C}$.

The next invention ${ }^{5}$ relates to protection of metals against corrosion and is designed for a preliminary treatment of the metal surface for the follow-up paint application. The method involves phosphatization of the metal surface in the aqueous solution and this is performed by spraying the aqueous solution on the metal surface for $40-60$ sec. at the point of entry into the phosphatization tank by immersing the metal into the phosphatization tank for $2.5 \mathrm{~min}$ and spraying the aqueous solution on the metal surface for $40-60 \mathrm{sec}$ at the output of the phosphatization tank with temperature of the aqueous solution being $35-40^{\circ} \mathrm{C}$.

In work $^{6}$, a metal surface is treated with aqueous solution containing zinc, nitrate, nickel, and chlorate ions; when fine-crystalline corrosion-resistant phosphate coating is to be obtained at phosphatization temperature $30-45^{\circ}$ within a period of time 2 to 10 minutes. The method is suitable in mechanical engineering, instrumentation engineering, and can also be applied when performing phosphatization of passenger compartments and cars and trucks bodies.

The authors of the invention ${ }^{7}$ studied the solution of phosphatization and a method of treatment of a metal surface with the solution and it is pertinent to treatment of metal surfaces, in particular, to phosphatization and may be used for protection of metals against corrosion in any branch of engineering industry and instrumentmaking industry at realization of painting activities. The solution contains a phosphorous-containing compound, an oxidizing agent neutralizing the component and water at pH 3.0-4.2.

A group of scientists developed a solution for phosphating a metal surface ${ }^{8}$. The solution contains (in g-L-): nitrate ions 1.8-6.5, chlorate ions 2.7-7.8, molybdenum ions $0.01-0.04$, and also phosphate ions (in terms of $\mathrm{P}_{2} \mathrm{O}_{5}$ ) 6.7-17.0 and calcium ions 0.9-3.5 in the form of a Khibini apatite concentrate. The application of the proposed solution allows to obtain phosphate coatings with high corrosion resistance, to use available technical raw materials for solution preparation.

In work $^{9}$, a brief overview of the current research worldwide in the chemical synthesis of copper nanoparticles is discussed. Chemical methods are used to synthesize copper nanoparticles and among them chemical reduction is the most frequently applied method for the preparation of stable, colloidal dispersions in organic solvents.

In paper $^{10}$, the chemical hazards of nanoparticles to human and environment were studied. This literature review has been commissioned to explore the physical and chemical properties of nanoparticles that could differentially influence toxicity, use of nanoparticles in industry and the potential hazards. This article has summarized the current state of knowledge on the potential risks posed by nanoparticles.

In next work ${ }^{11}$, the thermodynamic characteristics of the chemical interaction of zinc 
chloride with phosphoric acid were researched. It was found, that with the increase of the temperature and the duration of chemical interaction, a transformation degree of zinc and iron chlorides into phosphates increases and a residual content of chlorine in the products decreases simultaneously. A quality control of the received products was carried out using methods of chemical and crystal-optical analysis.

In paper $^{12}$, the technology for processing metal waste of phosphate compounds of metals was developed in order to use them as nanocoating. An adequate mathematical model with the best mode of the process was obtained.

When processing chloride sublimes containing $\mathrm{ZnCl}_{2}, \mathrm{PbCl}_{2}, \mathrm{CuCl}_{2}, \mathrm{FeCl}_{2}$, etc., the hydrometallurgical method produces non-ferrous metal salts, which are used to produce oxides, chlorides, sulfates and phosphates of metals. Processing zinc chloride with phosphoric acid makes it possible to obtain especially pure zinc phosphate, salts of lead and iron. The resulting zinc phosphates are used in the phosphatizing of metals and the preparation of mineral fertilizers or as corrosion inhibitors.

Therefore, the processing of zinc chloride on zinc phosphates is of both scientific and practical interest. It is necessary to study the kinetic parameters of the process of obtaining $\mathrm{Zn}\left(\mathrm{H}_{2} \mathrm{PO}_{4}\right)_{2}$ from zinc chloride. The presence of iron phosphate in the composition of zinc phosphate enhances the quality of phosphate coatings.

\section{METHODS AND MATERIALS}

Zinc phosphate is obtained from the chloride sublimates, containing $\mathrm{Zn}-18.3 \%$, $\mathrm{Cl}-28.9 \%$, others-62.8\%. After separation of insoluble impurities and chloride compounds $\left(\mathrm{FeCl}_{2}\right.$, $\mathrm{PbCl}_{2}$, etc.), the solution containing zinc chloride is treated with $45 \%$ phosphoric acid. Hydrochloric acid can be obtained from the hydrogen chloride evolved in this process.

Preliminary thermodynamic calculations show the probability of a reaction of the interaction of zinc chloride with phosphoric acid with the formation of $\mathrm{Zn}\left(\mathrm{H}_{2} \mathrm{PO}_{4}\right)_{2} \cdot 2 \mathrm{H}_{2} \mathrm{O}, \mathrm{FeHPO}_{4}$ and $\mathrm{HCl}$, as evidenced by the negative value $\left(-\Delta G T^{\circ}\right)$ of Gibbs energy. The calculation of the Gibbs energy values was carried out using a computer in the temperature range 298-433 K.

For obtaining zinc chloride, at the beginning of each cycle, a chloride sublimate in an amount of $100 \mathrm{~g}$ is dissolved at a temperature of $25^{\circ} \mathrm{C}$, while $\mathrm{PbCl}_{2}$ and an insoluble precipitate fall out in the precipitate. After filtration a solution, containing $\mathrm{ZnCl}_{2}$ and $\mathrm{FeCl}_{2}$ is treated by adding a stoichiometric amount of $73 \% \mathrm{H}_{3} \mathrm{PO}_{4}$. The formation of phosphates of zinc and iron occurs according to the following reactions (1) and (2).

$$
\begin{aligned}
& \mathrm{ZnCl}_{2}+2 \mathrm{H}_{3} \mathrm{PO}_{4}=\mathrm{Zn}\left(\mathrm{H}_{2} \mathrm{PO}_{4}\right)_{2}+2 \mathrm{HCl} \\
& \mathrm{FeCl}_{2}+\mathrm{H}_{3} \mathrm{PO}_{4}=\mathrm{FeHPO}_{4}+2 \mathrm{HCl}
\end{aligned}
$$

The process proceeds with intensive stirring in the temperature range $60-120^{\circ} \mathrm{C}$ and a duration of 40-60 minutes. In this case, hydrogen chloride is released into the gas phase, while $\mathrm{Zn}\left(\mathrm{H}_{2} \mathrm{PO}_{4}\right)_{2}$ and $\mathrm{FeHPO}_{4}$ are precipitated.

Quality control and investigation of the products obtained was carried out using chemical and crystal-optical methods of analysis. X-ray phase analysis was performed on the URS-50 IM device, differential-thermal analysis was performed on a derivatograph (Paulik, Aulik systems, etc.) in the temperature range $20-1000^{\circ} \mathrm{C}$ with a heating rate of $10 \mathrm{deg} /$ minutes. IR spectral analysis was performed on a UR-20 spectrometer in the frequency range from 400 to $3600 \mathrm{~cm}^{-1}$.

\section{RESULTS AND DISCUSSION}

The effect of temperature and duration on the degree of conversion of zinc and iron chlorides into metal phosphates ( $\alpha$ conv.) is given in Tables 1 and 2 , from which it follows that with increasing temperature and duration of interaction, the degree of conversion of zinc and iron chlorides into metal phosphates increases and simultaneously the residual chlorine content in the product decreases ${ }^{13}$.

This indicates that as the temperature increases in the liquid phase, the particles of a mixture of zinc and iron phosphates is formed in a large amount, and the amount of free phosphoric acid decreases. 
Table 1: Effect of temperature and duration of interaction on the degree of decomposition of zinc chloride

\begin{tabular}{|c|c|c|c|c|c|c|}
\hline \multirow[t]{2}{*}{ No } & \multirow[t]{2}{*}{ Temperature, ${ }^{\circ} \mathrm{C}$} & \multirow[t]{2}{*}{ Duration, min. } & \multicolumn{3}{|c|}{ Content of substances, $\%$} & \multirow[t]{2}{*}{ Degree of conversion, \% } \\
\hline & & & $\mathrm{P}_{2} \mathrm{O}_{5}$ & $\mathrm{ZnO}$ & $\mathrm{Cl}$ & \\
\hline 1 & 80 & 40 & 54,69 & 30,5 & 1,2 & 98,90 \\
\hline 2 & 80 & 60 & 54,71 & 31,2 & 0,9 & 99,05 \\
\hline 3 & 80 & 90 & 54,74 & 31,4 & 0,4 & 99,61 \\
\hline 4 & 100 & 40 & 54,60 & 31,1 & 0,12 & 99,90 \\
\hline 5 & 100 & 60 & 54,71 & 31,3 & abs. & 100 \\
\hline 6 & 100 & 90 & 54,71 & 31,36 & abs. & 100 \\
\hline 7 & 120 & 40 & 54,73 & 31,4 & abs. & 100 \\
\hline 8 & 120 & 60 & 54,73 & 31,4 & abs. & 100 \\
\hline
\end{tabular}

From the results given in Table 1 it can be seen that as the temperature and duration of interaction increase, the degree of conversion of zinc chloride into monozincphosphate increases and the residual chlorine content in the product decreases at the same time. The resulting hydrochloric acid containing $28-30 \%$ $\mathrm{HCl}$ meets the requirements, imposed on the quality of technical hydrochloric acid.
On the basis of the conducted research it is established that the optimal parameters of the process are the temperature of $100-120^{\circ} \mathrm{C}$, the duration of the interaction is $40-60$ minutes. The degree of conversion of zinc chloride into monozinc phosphate is $99.9-100 \%$, and chlorine is practically absent. Table 2 shows the results of decomposition of iron chloride with phosphoric acid.

Table 2. Effect of temperature and duration of interaction on the degree of decomposition of iron chloride

\begin{tabular}{|c|c|c|c|c|c|c|c|c|c|c|c|}
\hline \multirow[t]{2}{*}{ No } & \multirow{2}{*}{\multicolumn{2}{|c|}{ Temperature, ${ }^{\circ} \mathrm{C}$ Duration, min }} & \multicolumn{8}{|c|}{ Composition of the product } & \multirow{2}{*}{$\begin{array}{c}\text { Degree of } \\
\text { conversion } \\
\text { of } \mathrm{Cl}, \%\end{array}$} \\
\hline & & & $\begin{array}{c}\mathrm{FeHPO}_{4} \\
\mathrm{~g}\end{array}$ & $\%$ & $\begin{array}{c}\mathrm{FeCl}_{2} \\
\mathrm{~g}\end{array}$ & $\%$ & $\begin{array}{c}\mathrm{H}_{3} \mathrm{PO}_{4} \\
\mathrm{~g}\end{array}$ & $\%$ & $\begin{array}{c}\mathrm{H}_{2} \mathrm{O} \\
\mathrm{g}\end{array}$ & $\%$ & \\
\hline 1 & 80 & 30 & 3,54 & 11,8 & 2,02 & 6,71 & 1,07 & 3,56 & 23,45 & 77,94 & 74,0 \\
\hline 2 & 80 & 60 & 3,98 & 15,4 & 1,65 & 6,39 & 1,88 & 4,96 & 18,78 & 73,19 & 79,0 \\
\hline 3 & 80 & 90 & 4,18 & 15,5 & 1,48 & 4,23 & 1,14 & 4,23 & 20,44 & 74,50 & 81,0 \\
\hline 4 & 80 & 150 & 4,28 & 21,4 & 1,39 & 6,55 & 1,08 & 5,41 & 13,23 & 66,3 & 82,0 \\
\hline 5 & 120 & 30 & 3,64 & 11,4 & 1,89 & 5,71 & 1,47 & 4,44 & 26,07 & 78,7 & 76,0 \\
\hline 6 & 120 & 60 & 4,59 & 17,8 & 1,30 & 5,29 & 1,02 & 4,15 & 17,6 & 71,5 & 83,0 \\
\hline 7 & 120 & 90 & 4,96 & 22,9 & 0,82 & 3,8 & 0,13 & 2,91 & 15,2 & 70,4 & 84,0 \\
\hline 8 & 120 & 150 & 5,01 & 26,1 & 0,78 & 4,06 & 0,60 & 3,14 & 12,79 & 66,7 & 90,0 \\
\hline 9 & 170 & 30 & 1,77 & 6,29 & 1,49 & 5,3 & 2,09 & 7,44 & 20,8 & 73,8 & 55,0 \\
\hline 10 & 170 & 60 & 2,60 & 16,91 & 2,8 & 18,26 & 2,17 & 14,11 & 7,8 & 50,7 & 69,0 \\
\hline 11 & 170 & 90 & 4,49 & 48,2 & 1,21 & 12,9 & 0,94 & 10,12 & 2,67 & 28,7 & 84,0 \\
\hline 12 & 170 & 150 & 5,94 & 99,8 & - & - & - & - & 0,015 & 0,92 & 100 \\
\hline
\end{tabular}

Table 2 shows that with increasing the duration and temperature the yield of $\mathrm{FeHPO}_{4}$ increases, simultaneously the content of $\mathrm{FeCl}_{2}$ and a free acidity in product decreases. At the same time, the yield of $\mathrm{FeHPO}_{4}$ at $170^{\circ} \mathrm{C}$ is $5.94 \mathrm{~g}$ and chlorine is practically absent.

IR spectral analysis was performed on a UR-20 spectrometer in the frequency range from 400 to $3600 \mathrm{~cm}^{-1}$. The presence of the monoclinic form of $\mathrm{Zn}\left(\mathrm{H}_{2} \mathrm{PO}_{4}\right)_{2} \cdot 2 \mathrm{H}_{2} \mathrm{O}$ was confirmed by X-ray diffraction analysis with a full correspondence of the values between the interplanar distances $(d, A)$ and the relative intensities (I/I1) of the sample when surveying on a diffractometer.
Figure 1 shows $\mathrm{X}$-ray phase analysis of (a) $\mathrm{Zn}\left(\mathrm{H}_{2} \mathrm{PO}_{4}\right) 2 .{ }_{2} \mathrm{H}_{2} \mathrm{O}$ at $80^{\circ} \mathrm{C}$ and (b) $\mathrm{FeHPO}_{4}$ at $100^{\circ} \mathrm{C}$.

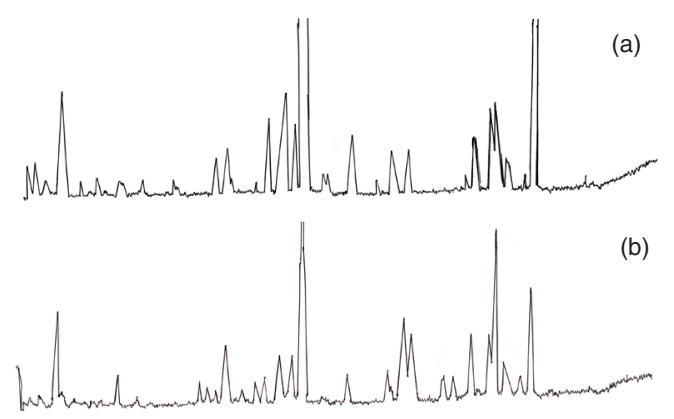

Fig. 1. X-ray diffraction pattern of zinc phosphate (a) and (b) iron phosphate precipitates 
The obtained product was studied by X-ray diffraction on a DRON-3 instrument in the interval 20-68 ${ }^{\circ}$, differential-thermal analysis on a derivatograph (Paulik, Pulik-Erdei) in the temperature range 20-1000 at a heating rate of $10 \mathrm{deg}-\mathrm{min}^{-1}$.

X-ray phase analysis data (d, A) show (Fig. 1) that in the diffraction pattern of zinc phosphate (a) the presence of monoclinic $\mathrm{Zn}\left(\mathrm{H}_{2} \mathrm{PO}_{4}\right)_{2} \cdot 2 \mathrm{H}_{2} \mathrm{O}$ and corresponds to the intensity $(1 / 11), 3.67,3.31$, 2, 93, 2, 78, 1, $97 \AA$, and in the diffraction pattern of iron phosphate (b) the presence of $\mathrm{FeHPO}_{4}$ and corresponds to the intensity $(1 / 11) 3,47 ; 3.02 ; 4.39 \AA$ and the presence of $\mathrm{FeCl}_{2}$ is practically not detected.

Derivatographic studies of products $\mathrm{FeHPO}_{4}$ (temperature $170^{\circ} \mathrm{C}$ and duration $90 \mathrm{~min}$ ) showed that in the temperature range $300-950^{\circ} \mathrm{C}$ thermal effects were fixed. The exothermic effect at $368,410^{\circ} \mathrm{C}$ is due to the conversion of $\mathrm{FeHPO}_{4}$ to $\mathrm{FePO}_{4}$, and at $810,950^{\circ} \mathrm{C}$ - by the melting of iron.

The derivatogram of $\mathrm{Zn}\left(\mathrm{H}_{2} \mathrm{PO}_{4}\right)_{2} \cdot 2 \mathrm{H}_{2} \mathrm{O}$, starting at $60^{\circ} \mathrm{C}$, sharply deflects the DTA curve from the baseline, caused by the endothermic effect in the temperature range $60-156^{\circ} \mathrm{C}$ and refers to the melting process of $\mathrm{Zn}\left(\mathrm{H}_{2} \mathrm{PO}_{4}\right)_{2} \cdot 2 \mathrm{H}_{2} \mathrm{O}$ in crystalline hydrate water and accompanied by a slight loss of mass $-2.12 \%$. The second endothermic effect at $232^{\circ} \mathrm{C}$ is caused by the removal of the crystalline hydrate and part of the constitutional water with partial condensation of mono-zinc phosphate $\mathrm{Zn}\left(\mathrm{H}_{2} \mathrm{PO}_{4}\right)_{2}$. As the sample is heated from 390 to $840^{\circ} \mathrm{C}$, further condensation and the appearance of several endothermic effects and a small loss of mass of the sample occur. The endothermic effect at 790 and $830^{\circ} \mathrm{C}$ corresponds to the polymorphous transformation of zinc metaphosphate and the melting of a mixture of zinc metaphosphate and pyrophosphate, and at $892^{\circ}$ corresponds to the melting process of all the decomposition products of mono-zinc phosphate. On the IR spectrum, the band with weakly expressed maxima at 3420 and $3600 \mathrm{~cm}^{-1}$ can be attributed to the valence vibrations of the $\mathrm{OH}^{-}$group and the formation of relatively strong hydrogen bonds. The band with a maximum at $1650 \mathrm{~cm}^{-1}$ corresponds to vibrations of water molecules, and the bands 640 and 585; 1025 and 950; 1150 and $1070 \mathrm{~cm}^{-1}$ probably indicate the complexity of the spectrum due to the low symmetry of the $\mathrm{H}_{2} \mathrm{O}_{4}$ - atom.
Thus, our studies have shown the possibility of obtaining zinc and iron chlorides, and iron monozinc phosphate and hydrophosphate, X-ray phase and IR spectral analysis for the presence of $\mathrm{Zn}\left(\mathrm{H}_{2} \mathrm{PO}_{4}\right)_{2} \cdot 2 \mathrm{H}_{2} \mathrm{O}$ and $\mathrm{FeHPO}_{4}$ and the absence of chlorine in the product.

Mass-spectrum analysis of the obtained zinc phosphate showed the presence of phosphorus content in the product is $8.42 \%$, zinc $43.89 \%$ and insignificant amount of chlorine $0.91 \%$ (Fig. 2), and the presence of iron $18.74 \%$, phosphorus $14.52 \%$ (Fig. 3). The size of phosphates ranges from $0.1 \mu \mathrm{m}$ to $100 \mu \mathrm{m}$. Such phosphate compounds meet the requirements of State standard and can be used as anticorrosive coatings for construction and products.

Thus, our studies have shown the possibility of obtaining zinc and iron phosphates from $\mathrm{ZnCl}_{2}$ and $\mathrm{FeCl}_{2}$, and X-ray phase analyzes for the presence of $\mathrm{Zn}_{2}\left(\mathrm{H}_{2} \mathrm{PO}_{4}\right)_{2} \cdot 2 \mathrm{H}_{2} \mathrm{O}$ and $\mathrm{FeHPO}_{4}$ in the product.
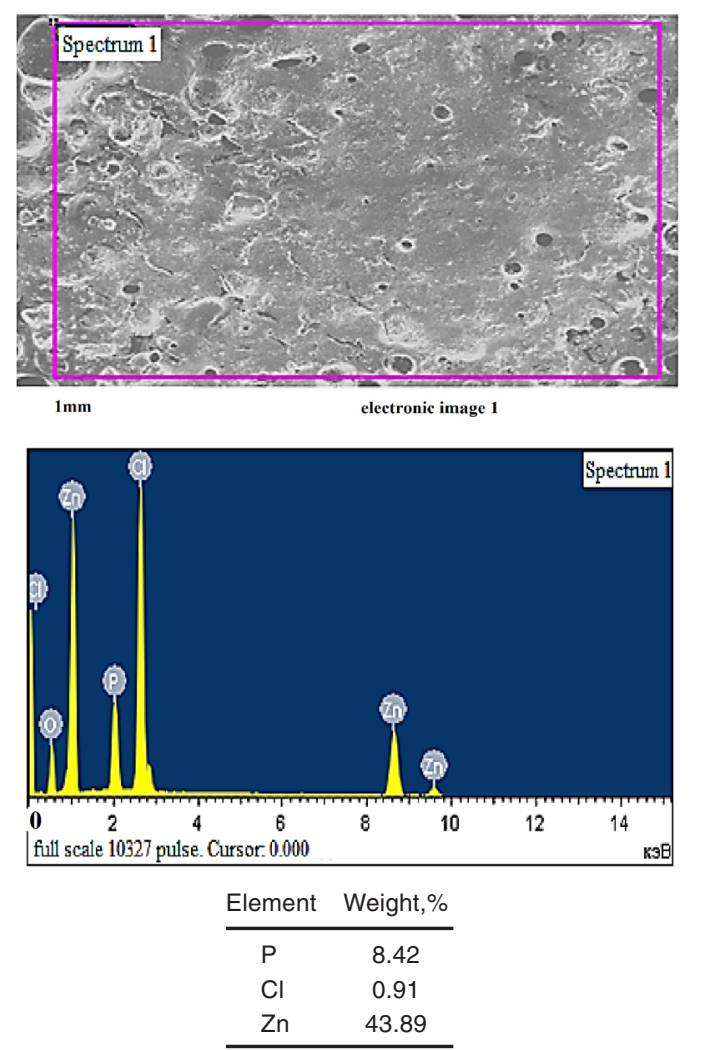

Fig. 2. Electronic image of the obtained zinc phosphate and its chemical composition 

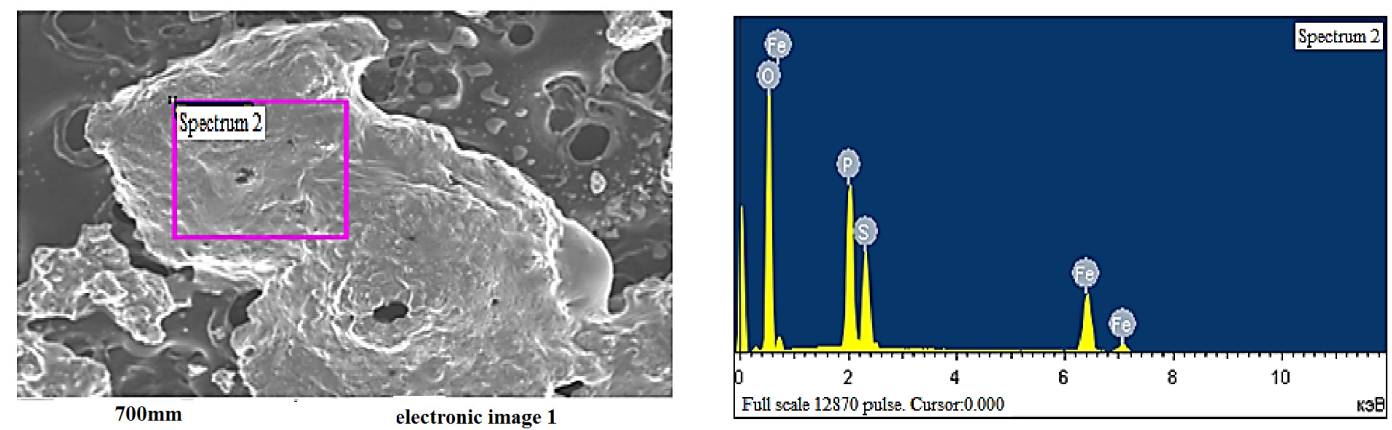

Fig. 3. Electronic image of the obtained iron phosphate and its chemical composition

\section{ACKNOWLOGEMENT}

Authors thanks the Committee of Science of the Ministry of Education and Science of the Republic of Kazakhstan for financial support under
Grant No 167-8 from 15.03.2018.

\section{CONFLICT OF INTEREST}

Conflict of interest is missing in manuscript.

\section{REFERENCES}

1. Zhuk N. P., Course in the theory of corrosion and protection of metals, Metallurgy, Moscow, 1989.

2. Anarbayev, A. A., Moldabekov, Sh.M., Almakhanov, B. A. Journal of Science and Education of Southern Kazakhstan., 2000, 3, 74-78

3. Shevko, V. M., Tomilin, I. A. and Complex use of mineral raw materials., 1993, 2, 48-51.

4. Russia Patent No 2209857, Zhesko, Yu. E., Zuber, D. L., Ivanova, L. D., Sgibneva, V. I., Composition and methods of application of phosphate and chromium coats., 2003 10, 08.

5. Russia Patent No 2365675, Chumaevsky, V. A., Bonokina, M. N., Zhuravleva, S. L., Kesaeva, L. V., Kobelkova, E. V., A method for obtaining phosphate coating., 2009, 27.08.

6. Russia Patent No 2240378, Varentsova, N. V., Chumaevsky, V. A., Bonokina, M. N. and etc., Phosphate coating manufacture method., 2004, 20, 11.

7. Russia Patent No 2251590, Vdovin, A. V., Kauzova, I. A., Krasnova, T. M., Maltseva, N. V., Krutikov, D. V., Solution of phosphatization and a method of treatment of a metal surface with the solution., 2005, 10, 05.

8. Russia Patent No 96123582, Krasnova, T. M., Maslova, E. Kh., Chumaevsky, V. A., A solution for phosphating a metal surface., 1998, 10, 09.

9. Hamid Reza Ghorbani. Orien. J. Chem., 2014, 30(2), 803-806.

10. Fozia Haque Khan. Orient. J. Chem., 2013, 29(4), 1399-1408.

11. Anarbayev, A.A., Kabylbekova, B.N., Aikozova, L.D., Vysozkaya, N.A., Spabekova R., Journal of Characterization and Development of novel Materials., 2013, 211-217.

12. Aikozova L.D., Bayysbai O. P., Isaeva R.R., Shyngisbaeva Zh.A. The collection of materials of the XII International Scientific Practical Conference "Integration of science and practice in modern conditions", Moscow, 2018, 79-82.

13. Anarbaev, A.A., Myrkhalykov, Zh.U., Saipov, A.A., Kabylbekova, B.N., Tukibaeva, A.S. Synthesis technology of nanostructured anti-corrosion protective coatings for structural products and materials, Gylym, Almaty., 2014. 